\title{
O ENSINO MÉDIO INTEGRADO NO CONTEXTO DA AVALIAÇÃO POR RESULTADOS*
}

\author{
Katharine Ninive Pinto Silva ${ }^{1}$ \\ Marise Ramos ${ }^{2}$
}

\begin{abstract}
RESUMO: Este artigo apresenta resultados parciais de uma pesquisa que teve como objetivo geral refletir sobre a relação entre as políticas de avaliação por resultados e a implementação da proposta curricular do ensino médio integrado. Como metodologia, analisamos documentoseentrevistas realizadas com docentes e gestores das redes federal e estadual de Pernambuco, com base nas categorias gerais do materialismo histórico-dialético. Concluímos que os resultados das avaliaçóes externas são a referência de qualidade das políticas educacionais na atualidade, pressionando o ensino médio integrado por meio da ênfase em escores e ranqueamentos e norteando a organizaçáo dos currículos de maneira a ampliar os problemas da dualidade entre a formaçáo propedêutica e a formação técnico-profissional.
\end{abstract}

Palavras-chave: Ensino médio integrado. Avaliação por resultados. Ensino médio. Educação profissional.

\section{INTEGRATED HIGH SCHOOL IN THE CONTEXT OF EVALUATION BY RESULTS}

ABSTRACT: This article presents partial results of a research whose general objective was to reflect on the relationship between the policy of evaluation by results and the implementation of the curricular proposal of integrated high school. Our methodology was to analyze documents and interviews with teachers and managers from the Federal and State school networks in Pernambuco, based on general categories of historical-dialectical materialism. We concluded that the results of the external evaluations are nowadays the reference for quality of educational policies, pushing the integrated high school proposal by putting emphasis on scoring and ranking, thus guiding the organization of curricula as to widen duality problems between preparatory and technical training.

Keywords: Integrated high school. Evaluation by results. High school. Professional education.

\footnotetext{
*Artigo derivado do Projeto de Pesquisa Ensino Médio IntegrallIntegrado elou em Jornada Ampliada no contexto da Avaliação por Resultados: os Desafios para o Trabalho Docente, apoiado pelo Conselho Nacional de Ciência e Tecnologia (CNPq), chamada universal no 14/2013.

${ }^{1}$ Universidade Federal de Pernambuco - Recife (PE), Brasil. E-mail: katharineninive@gmail.com

${ }^{2}$ Universidade do Estado do Rio de Janeiro - Rio de Janeiro (RJ), Brasil.

E-mail: ramosmn@gmail.com

DOI: 10.1590/ES0101-73302018186794
} 


\section{ÉDUCATION SECONDAIRE INTÉGRÉE DANS LE CONTEXTE DE L'ÉVALUATION PAR RÉSULTATS}

RÉSUMÉ: Cet article présente les résultats partiels d'une recherche dont l'objectif général a été de réfléchir sur la relation entre la Politique d'Evaluation par Résultats et la mise en œuvre de la proposition du programme d'éducation secondaire intégrée. La methodologie suivie a été l'analyse des documents et entretiens avec enseignants et gestionnaires des réseaux scolaires fédérales ou de l'État à Pernambuco, sur la base du matérialisme historique-dialectique. On conclut que les résultats des évaluations externes sont la référence de la qualité des politiques éducatives aujourd'hui, pressant l'éducation secondaire intégrée en mettant l'accent sur les scores et les classements, en guidant l'organisation des programmes d'études afin d'élargir les problèmes de dualité liés àla formation pratique et à la formation technique.

Mots-clés: Éducation secondaire intégrée. Évaluation par résultats. Lycée. Éducation professionnelle.

\section{Introdução}

$\mathrm{E}$

ste artigo trata de resultados parciais da pesquisa sobre o ensino médio integrado (EMI) em instituiçóes federais e estaduais em relação às políticas

de avaliação por resultados, buscando responder à seguinte questão: quais são as pressóes das políticas de avaliação por resultados nas propostas de EMI?

Por políticas de avaliação por resultados, consideramos, assim como Apple (2015), aquelas associadas ao novo gerencialismo, expressão de uma coalizão entre neoliberais e neoconservadores. Tais políticas seguem as orientaçóes dos organismos internacionais, que ponderam a qualidade da educação com base nos pressupostos quantitativos, sendo incentivados programas de avaliação externa tais como o Program for International Student Assessment (PISA).

O Brasil acompanha essa associação, ao definir a qualidade da educação levando em conta os resultados no Índice de Desenvolvimento da Educação Básica (IDEB), desde o lançamento do Decreto no 6.094/2007 — Plano de Metas Compromisso Todos pela Educação - e do Plano de Desenvolvimento da Educação (PDE) (BRASIL, 2007a). No Plano Nacional de Educação (BRASIL, 2014a), essa também é a referência de qualidade da educação, o que, para Gesqui (2016, p. 93), "desestimula - ao menos durante sua vigência - a necessária continuidade do debate acadêmico e legal sobre o conceito de qualidade da educação básica nacional”"

Dessa forma, no contexto nacional, o Brasil adota uma política gerencialista, com ênfase na avaliação por resultados. Ainda no que se refere às políticas 
de avaliação por resultados, é importante também caracterizar o Exame Nacional do Ensino Médio (ENEM), instituído pela Portaria no 438/1998. De acordo com Bormann (2017), o exame vem influenciando a definiçẫo de programas de governo e as reestruturaçóes curriculares.

Para Silva e Silva (2016), a rede estadual de Pernambuco também seguiu a mesma direção, por intermédio da implantação do Programa de Modernização da Gestáo Pública - Metas para a Educação (PMGP-ME). Segundo os autores:

O PMGP-ME foi criado em parceria com o Movimento Brasil Competitivo (MBC) e o Instituto de Desenvolvimento Gerencial (INDG), voltado para a melhoria dos indicadores educacionais do Estado. Por meio do Programa, são estipuladas metas verticalizadas para cada Escola, envolvendo a conjugação de três fatores: 1. uma avaliação própria do desempenho dos alunos em Língua Portuguesa e Matemática; 2. o Sistema de Avaliação da Educaçáo de Pernambuco (SAEPE), que combinado com o fluxo escolar, define o resultado do Índice de Desenvolvimento da Educação de Pernambuco (IDEPE), ou seja, um índice próprio de qualidade e 3. O Bônus de Desempenho Educacional (BDE), o chamado décimo quarto salário que é destinado apenas às escolas que atingiram a partir de $50 \%$ da meta estipulada pelo PMGP-ME. Articulada a esta estratégia de bonificação, existe também uma estratégia de sanção por meio da exposição pública dos resultados e do ranqueamento das escolas (SILVA; SILVA, 2016, p. 746).

Quanto ao EMI, reconhecemos duas dimensões. Uma delas é formal, referente à possibilidade de integração da educação profissional ao ensino médio. A outra é conceitual, pois representa um projeto de formação integral dos estudantes integrado ao ensino médio.

A forma integrada da educação profissional ao ensino médio foi inicialmente prevista pelo Decreto no 5.154/2004 (BRASIL, 2004), tendo seu conteúdo sido incluído na Lei de Diretrizes e Bases da Educação Nacional (LDB), pela Lei $\mathrm{n}^{\circ} 11.741$, de 2008 (BRASIL, 2008a). Trata-se de uma das modalidades de articulação entre a educação profissional técnica e o ensino médio, cujo sentido está no compromisso ético e político de assegurar aos estudantes, em um único currículo, o direito à formação profissional, sem que esta substitua a formação geral, tal como foi descrito no parágrafo segundo do artigo 36 da versão original da LDB.

Sua concepção, porém, ultrapassa o aspecto formal da integração entre as finalidades formativas, implicando também a integração entre trabalho, ciência e cultura - dimensóes fundamentais da prática social — no projeto político-pedagógico que visa à formação integral e integrada dos estudantes. Ao ser visto como uma concepção de formação humana, o EMI adquire um sentido filosófico e epistemológico que não admite a simples junção de disciplinas consideradas de formação 
profissional ou de formação geral no currículo. Antes, ele objetiva proporcionar a compreensão da relação econômica, social e histórica entre essas dimensóes da prática social, mediante um currículo que leve à apreensão de conceitos como sistema de relaçóes de uma totalidade concreta que se pretende explicar, compreender e transformar (RAMOS, 2017).

Considerando tais elementos, este artigo apresenta resultados parciais de uma pesquisa que teve como objetivo geral refletir sobre a relação entre as políticas de avaliação por resultados e a implementação da proposta curricular do EMI nessas experiências. Tais resultados respondem aos seguintes objetivos específicos: analisar as concepçóes de EMI dos gestores e docentes das escolas técnicas estaduais (ETEs) de Pernambuco e do Instituto Federal de Educação, Ciência e Tecnologia de Pernambuco (IFPE) pesquisados; e refletir sobre as relaçóes que os entrevistados estabelecem entre as políticas de avaliação por resultados e a proposta curricular implementada.

Para tanto, na busca da unidade entre a investigação histórica e a exposição lógica dos resultados obtidos, consideramos, assim como Gramsci (2000), que os elementos da observação empírica devem "ser situados nos vários níveis das relaçóes de forças, a começar pela relação das forças internacionais " "GRAMSCI, 2000, p. 20), tais como as grandes potências, os agrupamentos de Estados em sistemas hegemônicos e os conceitos de independência e soberania, além das relaçóes objetivas sociais e das relaçóes de força política que dizem respeito, respectivamente, ao desenvolvimento das forças produtivas e aos sistemas hegemônicos do Estado. A influência de fatores globais sobre políticas nacionais, como as manifestadas pelo PISA e pelos mecanismos de diálogo e assessoramento de organismos internacionais, bem como a ação de representantes locais desses interesses, como o movimento Todos pela Educação, constitui um elemento a ser levado em conta em estudos sobre políticas educacionais.

Os procedimentos metodológicos envolveram a análise documental e a realização de entrevistas semiestruturadas com 13 docentes e dois gestores das ETEs e nove docentes e um gestor do IFPE. Os trechos das entrevistas citadas neste artigo tiveram os nomes dos depoentes trocados por nomes escolhidos por eles. Tais dados foram analisados considerando as categorias gerais do materialismo histórico-dialético (contradição, totalidade, reprodução, mediação e hegemonia) e suas relaçóes com a educação (CURY, 1995). Como método de exposição, apresentamos os resultados das análises articulando os achados empíricos e teóricos sobre as concepçóes em disputa no EMI e sobre as influências das avaliaçóes externas no seu currículo.

\section{Ensino médio integrado: concepções em disputa}

A educação profissional no Brasil foi regulamentada pelo Decreto $\mathrm{n}^{\mathrm{o}} 5.154$, de 23 de julho de 2004 (BRASIL, 2004) ${ }^{3}$, e parte do teor inicial dele 
foi alterada pelo Decreto no 8.268, de 18 de junho de 2014 (BRASIL, 2014b), que inseriu os termos qualificação profissional e itinerários formativos no artigo $1^{\circ}$, ampliando possibilidades da formaçáo inicial e continuada de trabalhadores e da educação profissional técnica de nível médio. Em 2008, a Lei no 11.741 (BRASIL, 2008a) incluiu na LDB os dispositivos sobre as formas de articulaçáo entre a educação profissional técnica de nível médio e o ensino médio.

De acordo com Boanafina, Boanafina e Wermelinger (2017, p. 79), o Decreto no 5.154 de 2004 (BRASIL, 2004) pode ser considerado "híbrido", por ser o "resultado do embate entre as forças conservadoras, defensoras dos interesses do mercado, e as progressistas, comprometidas com as políticas socioeducacionais que privilegiam a formação integral do ser humano". Já autores como Frigotto, Ciavatta e Ramos (2005, p. 4) acreditam que devemos interpretar o Decreto de 2004 como "ganho político e, também, como sinalização de mudanças [...] ou será apropriado pelo conservadorismo, pelos interesses definidos pelo mercado".

Ao refletirmos sobre as concepçóes em disputa em relação ao EMI na realidade das ETEs e do IFPE, é preciso levar em conta, primeiramente, as distinçóes e semelhanças que existem entre esses dois tipos de instituição e projeto. Essas disparidades começam pelo fato de pertencerem a redes de ensino diferentes.

Os Institutos Federais fazem parte da Rede Federal de Educação Profissional, Científica e Tecnológica (RFEPCT) e foram criados mediante um novo agrupamento das escolas técnicas, agrotécnicas e centros federais de educação tecnológica, juntamente com a instituição dessa rede no âmbito do sistema federal de ensino, por meio da Lei no 11.892 , de 29 de dezembro de 2008 (BRASIL, 2008b), como

instituições de educação superior, básica e profissional, pluricurriculares e multicampi, especializados na oferta de educação profissional e tecnológica nas diferentes modalidades de ensino, com base na conjugação de conhecimentos técnicos e tecnológicos com as suas práticas pedagógicas, nos termos desta Lei.

Com tantas atribuições, os Institutos Federais são equiparados, de acordo com essa lei, às universidades federais. Os entrevistados do IFPE, considerando tal contexto, dão ênfase ao fato de o EMI na instituição ainda ser algo em construção, como podemos exemplificar com o trecho a seguir:

O Instituto Federal, ele ainda está procurando esta identidade, [...] e nós estamos fazendo os quatro papéis. [...] Estamos fazendo as quatro áreas, patinando no meio dessas quatro áreas diferentes. Então, no fim, acho muito difícil haver uma cultura de êxito nas quatro áreas. Fica complicado, porque você cria todo um corpo docente, um corpo de gestor especializado em uma área. [...] E a gente tem um professor de ensino médio, ensino técnico, subse- 
quente e ensino superior. Então, ele vai atuar em quatro diferentes níveis, quatro diferentes propostas. $\mathrm{E}$, além disso, tem a pesquisa e extensão também, que podem englobar todos os quatro (Fábio Júnior - IFPE).

Para Boanafina, Boanafina e Wermelinger (2017), a expansão da RFEPCT foi expressiva nos últimos anos:

\begin{abstract}
Essa expansão [...] ocorreu a partir de 2003 com um significativo crescimento da rede federal, que chegou, em 2013, a 467 unidades em 393 municípios, com perspectivas de atingir 592 unidades até o final de 2015. Se comparada com o crescimento entre os anos de 1909 e 2002, onde foram construídas 140 escolas técnicas em 118 municípios (BOANAFINA; BOANAFINA; WERMELINGER, 2017, p. 82).
\end{abstract}

No entanto, diante do tamanho da rede e das suas exigências, o Tribunal de Contas da União (TCU) realizou auditoria (Relatório de número TC.026.062/2011-9) e firmou um acórdão (no 506/2013) com recomendações à Secretaria de Educação Profissional e Tecnológica (SETEC), em conjunto com os Institutos Federais, em torno de açóes que visassem à diminuição da evasão nos institutos.

Já no tocante ao EMI nas redes estaduais de ensino, como mostra Ferreira (2017, p. 305-306), o Ministério da Educação, durante o governo Lula, procurou "induzir adoção de programas pelos estados por meio de apoio técnico financeiro". Esse foi o caso de dois programas que identificamos na implementação do EMI na rede estadual de Pernambuco, "diretamente relacionados à ampliação do número de matrículas no Programa de Educação Integral (PEI)" (SILVA; SILVA, 2017, p. 242): o Programa Brasil Profissionalizado, instituído por meio do Decreto no 6.302, de 12 de dezembro de 2007 (BRASIL, 2007b), e o Programa Ensino Médio Inovador (ProEMI), estabelecido pela Portaria no 917, de 9 de outubro de 2009 (BRASIL, 2009).

O Programa Brasil Profissionalizado foi originalmente criado com a finalidade de apoiar a implantação do EMI nos sistemas estaduais de ensino, porém o EMI deixou de ser prioridade com o Programa Nacional de Acesso ao Ensino Técnico e Emprego (Pronatec), criado pela Lei no 12.513/2011 (BRASIL, 2011).

O ProEMI também é um programa voltado a apoiar as secretarias estaduais e distrital da Educação, mas no que concerne ao "desenvolvimento de açôes de melhoria da qualidade do ensino médio não profissionalizante" (BRASIL, 2009), tendo como principais objetivos, segundo Bormann (2017, p. 23) "apoiar e fortalecer o desenvolvimento de propostas curriculares inovadoras nas escolas de ensino médio, ampliando o tempo dos estudantes na escola e buscando garantir a forma- 
ção integral com a inserção de atividades que tornem o currículo mais dinâmico". O ProEMI visa orientar os sistemas de ensino e as escolas para a formulação de seus Projetos de Redesenho Curricular (PRC), que devem ser feitos de acordo com o que estabelecem as Diretrizes Curriculares Nacionais para o Ensino Médio (DCNEM) (BRASIL, 2012a). Esses PRC têm de ser elaborados, nesse sentido, com atividades integradoras que vejam o trabalho, a ciência e a tecnologia como dimensões indissociáveis da formação humana.

É importante considerar que, nas Diretrizes Curriculares Nacionais da Educação Profissional (DCNEP) (BRASIL, 2012b), a educação integrada é compreendida somente como uma das formas de desenvolvimento da educação profissional técnica de nível médio. Já as DCNEM (BRASIL, 2012a) se referem, em seu artigo 5, à "formação integral do estudante" e "integração entre educação e as dimensóes do trabalho, da ciência, da tecnologia e da cultura como base da proposta e do desenvolvimento curricular". Logo, "o trabalho é conceituado na sua perspectiva ontológica de transformação da natureza, como condiçáo inerente ao ser humano e como mediação no processo de produção de sua existência" (BRASIL, 2012a).

Curiosamente, ao observamos a relação entre as mençóes à qualificação e às competências nas DCNEM (BRASIL, 2012a) e nas DCNEP (BRASIL, 2012b), verificamos que o termo qualificą̧āo profissional é utilizado para caracterizar as etapas de ensino, como sinônimo de especialização profissional. Esse é um entendimento restrito da qualificação, porque se contradiz com as determinaçôes ontológicas e históricas do trabalho, para a qual convergiria o conceito de qualificação como relação social. Por isso, a qualificação não é apenas um estoque de conhecimentos aprendidos formalmente e legitimados por um diploma. Antes, ela incorpora elementos da relaçáo do trabalhador com seu trabalho - quando se manifestam seus saberes reais, por vezes vistos como suas competências - e com seu grupo profissional, nos sentidos tanto corporativos quanto ético-políticos (RAMOS, 2001). Já a palavra competência é usada pela perspectiva de aptidáo para cumprir alguma tarefa ou função, empregada conjuntamente com conhecimentos e saberes profissionais requeridos pelo mercado de trabalho. Nesse caso, a competência adquire um conteúdo psicológico, ignorando-se a complexidade que implica a ligação entre sujeito, objeto do conhecimento e relações de trabalho.

No entanto, haja vista as entrevistas realizadas, identificamos a predominância da concepção de educação integrada como qualificaçấo para o mercado obtida mediante o desenvolvimento de competências, saberes e aquisição de conhecimentos requeridos. O trecho a seguir é exemplar: "Eu acho interessante que o aluno tenha, fora o ensino médio, um curso que lhe dê oportunidade de ingressar no mercado de trabalho, assim que terminar o ensino médio, com uma formação especifica" (X — IFPE). Essa foi a concepção predominante entre os entrevistados, e os docentes e gestores das ETEs criticaram o fato de o currículo da educação profissional ser pressionado pela quantidade de disciplinas propedêuticas, especialmente 
voltadas para as que são consideradas nas avaliaçóes externas, como podemos ver neste depoimento: "Escola de tempo integral técnica, eu acho que falta muito essa coisa do técnico. Então ela está mais parecida com escola regular" (Elvira - ETE).

$\mathrm{Na}$ rede estadual de ensino de Pernambuco, a educação integrada está associada com o tempo integral e com uma proposta de educação integral. O termo tempo integral, no Brasil, de acordo com Rosa, Marcondes e Coelho (2016), é definido pela Lei no 10.172/2001 — do PNE — e do Decreto no 6.253/2007 — do Fundo de Manutenção e Desenvolvimento da Educação Básica e de Valorização dos Profissionais da Educação (FUNDEB) - como um período de no mínimo sete horas diárias na escola. Já a proposta de educação integral da rede estadual de ensino de Pernambuco, para Silva e Silva (2016, p. 745-746),

se fundamenta na concepção de educação interdimensional (COSTA, 2008), que pressupóe exercício da cidadania e protagonismo juvenil, compreendendo "açôes educativas sistemáticas voltadas para as quatro dimensóes do ser humano: racionalidade, afetividade corporeidade e espiritualidade". [...] Esta concepção articula-se no PEI à perspectiva de planejamento estratégico aplicado à área educacional, que tem como proposta realizar planejamento estratégico aplicado às escolas.

Tal perspectiva de educação interdimensional toma como base o modelo de educação por competências, pensando nos quatro pilares da educação, que săo as aprendizagens que constituem o eixo estruturador para a educação no século XXI do Relatório Jacques Delors (UNESCO, 1997): aprender a ser, aprender a conviver, aprender a fazer e aprender a conhecer.

Quando consideramos os documentos oficiais e as entrevistas com os docentes e gestores, identificamos a existência das seguintes concepçôes de educaçáo integrada em disputa: por um lado, uma concepção no sentido do que preconizam as DCNEM, como a integração entre trabalho, ciência, tecnologia e cultura, ideia mais presente na proposta e nas falas dos docentes e gestores das ETEs, mesmo com uma disputa clara com o outro tipo de concepção; e, por outro lado, uma concepção de integraçáo como uma das formas de realização da educação profissional técnica articulada ao ensino médio, ou seja, integrando a formação propedêutica à qualificação profissional.

Não obstante, tanto de uma concepção quanto da outra faz parte a perspectiva da empregabilidade e da formação por competências. Isso conforma uma contradição na práxis pedagógica, a qual desvela, no plano empírico, a disputa travada na formulação dos textos oficiais entre a concepção pragmática que caracteriza a formação por competências (RAMOS, 2016), na ótica do mercado de trabalho, e a concepção de formação integrada na visão da formação humana, 
a qual visa proporcionar aos estudantes a compreensão da relação econômica, social e histórica entre as dimensóes da prática social como uma totalidade concreta.

\section{As influências das avaliações externas no currículo do Ensino Médio Integrado}

De acordo com Freitas (2014), a pressão de exames nacionais e internacionais trouxe alguns rebatimentos para a organizaçáo do trabalho pedagógico da escola, tais como: o alinhamento da escola a concepçóes didáticas que julgávamos já superadas, como, por exemplo, o (neo)tecnicismo; a imitação da organização do trabalho da iniciativa privada, especialmente no tocante à priorização do controle do processo por meio de estratégias de padronização e automação das atividades; e o monitoramento e as recompensas contingentes aos índices.

A maioria dos nossos entrevistados considera que as avaliaçóes externas influenciam na organização do trabalho pedagógico do EMI. Apenas para uma minoria dos entrevistados do IFPE, essa influência é pequena, ou não existe. Para os que acreditam que a influência é pequena, a justificativa é o fato de, apesar de a ênfase da instituição ser na formação técnico-profissional, os alunos se saírem bem nas avaliações externas:

A gente mostra bons resultados neles também, mas também em olimpíadas do conhecimento e em outras aferiçóes. Mas a influência direta do ENEM e do IDEB no nosso currículo, ela está muito modesta. Modesta porque principalmente o nosso foco inicial não é o ENEM, né? Quando você olha para o ENEM, você prepara aquele aluno para concluir o ensino médio e ingressar numa universidade. Quando a gente já oferta o médio integrado ao técnico, dá uma desvirtuada, uma fugida desse caminho, né? (Fernando - IFPE).

No entanto não se tem um questionamento desses entrevistados quanto ao fato de, na instituição, existir um processo seletivo muito concorrido. Mesmo com a política de cotas empregada, a instituição já recebe os alunos mais qualificados no ponto de partida, o que faz com que também venham a aparecer melhor nas estatísticas em geral. Esse fenômeno converge com a conclusão de Freitas (2012, p. 384) de que "há uma alta correção entre a proficiência inicial e a final, ou seja, quem entra com proficiência alta termina também com alta em relação aos demais alunos".

Os entrevistados do IFPE que consideram não haver influência das avaliações externas justificam sua posição pela questão de trabalharem com disciplinas da área técnica no fim do curso, das quais só participam aqueles que não passaram no ENEM e, por esse motivo, não abandonaram a formação técnica. 
"Olha, eu não posso dizer pelos outros, mas para as minhas disciplinas é completamente irrelevante porque o meu, as minhas disciplinas, não cai no ENEM" (Eduardo - IFPE). Ao mesmo tempo, contraditoriamente, na justificativa, há referência de como as avaliaçôes externas interferem no desenvolvimento do EMI, manifestada na evasão dos alunos aprovados para o ensino superior:

\begin{abstract}
Acho que essa pressão se dá por medo da evasão, porque o que muitos alunos fazem: chegam ao terceiro ano, prestam vestibular e vão embora. Aí aqui ainda não foi bem discutido isso, não chegou em um consenso do que precisamos alterar na grade, se quiser deixar o estudante aqui. Eles colocam umas disciplinas espalhadas para prender o aluno, mas não prende, porque ele passa. Com a autorização do juiz, ele assume a vaga. Entáo tá muito complicado, mas isso ainda é tabu (Antônio - IFPE).
\end{abstract}

Trata-se de uma evasão às avessas, isto é, aquela provocada pelo bom desempenho do estudante, em confronto com o tipo de evasão mais comumente conhecido, que se deve ao baixo desempenho do aluno.

A influência que os entrevistados das duas redes atribuem às avaliaçóes externas no que tange à organização do trabalho pedagógico nas escolas, considerando a oferta do EMI, é caracterizada tanto de forma positiva quanto negativa. As avaliações positivas são de duas ordens. Há aqueles que acreditam que os resultados das avaliaçóes externas permitem avaliar melhor os alunos: "Essas avaliaçôes externas fazem com que a gente verifique como está sendo a aprendizagem do aluno, como esse aluno está sendo preparado, para tanto o mercado de trabalho como para a vida profissional' (Professora - ETE). Também há aqueles que creem que sociedade e escola funcionam pela perspectiva da meritocracia e, dessa maneira, as avaliaçóes externas são adequadas para a melhoria da qualidade da educação:

Olhe, considerando que a sociedade hoje assimilou a realidade da busca por resultados, a escola buscar esses resultados transfere pra sociedade a imagem da boa e da má escola. [...] Boas classificaçōes nas avaliaçôes externas, em particular o IDEB e o IDEPE, importante pra que a escola possa se assumir perante a sociedade, como uma escola de qualidade (José Mota - ETE).

Deve nortear. Porque são avaliaçôes externas que os alunos vão estar submetidos na realidade do Brasil. $\mathrm{O}$ aluno, ele não tá aqui pra ser aprovado somente dentro do colégio. Ele tem que sair com a capacidade de ser aprovado em qualquer avaliaçáo externa que ele necessitar e quiser fazer (Gerson - IFPE).

Sobre a questáo da meritocracia, Freitas (2012) situa-a no sistema de responsabilização, que, segundo o autor, envolve 
testes para os estudantes, divulgação pública do desempenho da escola e recompensas e sanções [...]. As recompensas e sançóes compóem o caráter meritocrático do sistema, mas não só, já que a própria divulgação pública dos resultados da escola constitui em si mesma uma exposição pública que envolve alguma recompensa ou sançóes públicas (FREITAS, 2012, p. 383).

Entre os que avaliam de modo negativo a influência das avaliaçóes externas na organização do trabalho pedagógico nas escolas, está a denúncia de que estas promovem o estreitamento curricular no EMI, seja porque enfatizam algumas disciplinas, seja porque acarretam a falta de ênfase na formação técnica. Nesse caso, porém, a preocupação ainda é mais com a formação para o mercado de trabalho do que com a formação integrada na perspectiva da formação humana:

Esse é outro problema sério, porque parece que a escola só tem duas disciplinas, Português e Matemática. E, infelizmente, todo movimento dentro da escola é para que os alunos se saiam bem em Língua Portuguesa e Matemática, como se as outras disciplinas não contribuíssem para a formação do indivíduo (Adailton — ETE).

A escola técnica acaba sendo uma escola como outra qualquer, [...] ela não observa a questão do mercado de trabalho. Então, às vezes, a gente está preparando o aluno apenas para o ENEM ou para o IDEB, ao invés de estar preparando para o mercado de trabalho (Elvira - ETE). na educação:

Outros entrevistados apontam os limites das abordagens quantitativas

Sou contra todas as mensuraçóes que venham somente fazer análise quantitativa. Se o Instituto Federal tem esse tipo de análise, eu pessoalmente não aceito. [...] Nem a escola pode estar sob esse tipo de pressão, de metas (Fábio Júnior — IFPE).

Freitas (2012, p. 389) chama a atenção para o fato de que "avaliaçóes geram tradiçóes". Ou seja, "quando os testes incluem determinadas disciplinas e deixam outras de fora, os professores tendem a ensinar aquelas disciplinas abordadas nos testes” (FREITAS, 2012, p. 389). Há, então, ênfase na cognição em detrimento das outras dimensóes da matriz formativa. A esse fenômeno o autor se refere como estreitamento curricular. Além disso, no âmbito mesmo do conhecimento cognitivo, "a proposta dos reformadores empresariais é a ratificação do currículo básico, mínimo, como referência” (FREITAS, 2012, p. 389). No caso brasileiro, essa perspectiva vem disputando as várias diretrizes curriculares (entre as quais destacamos as do ensino médio e da educação profissional), bem como na atualidade, de acordo com Ferretti e Silva (2017, p. 387), 
vem norteando a Base Nacional Comum Curricular (BNCC) $)^{4}$ e a contrarreforma do ensino médio (BRASIL, 2017).

A questáo do estreitamento curricular no EMI, haja vista pressão dos resultados nas avaliaçóes externas, revela maior complexidade no processo de integração entre a formação técnica profissional em nível médio e a formação de nível médio prevista na legislação (BRASIL, 2004; 2012a; 2012b; 2014b). Questôes como a dualidade entre a formação técnica, voltada para o mercado de trabalho, e a formação propedêutica, direcionada à continuidade dos estudos em nível superior, ganham novos contornos. Caú (2017) identificou no EMI do IFPE elementos da dualidade histórica decorrente da fragmentaçấo do currículo no que diz respeito à formação profissional e à formação geral, em depoimentos de jovens alunos dessa modalidade de ensino.

No entanto, existem outras concepçóes de como organizar os sistemas de ensino, como o finlandês, por exemplo. Levando em conta essa comparação, de acordo com Moraes (2017, p. 408),

é possível afirmar que países cujos sistemas de ensino praticam menos a segregação precoce e favorecem a manutenção de um "tronco comum" por mais tempo na escolaridade básica obrigatória săo os que alcançam melhores resultados educacionais, inclusive no PISA.

Nesse mesmo sentido, para Freitas (2016, p. 128),

focar em índices de avaliação associados à auditoria, acreditando que o aumento nas médias de desempenho é sinônimo de boa educação, desresponsabiliza aquelas forças positivas, no interior das instituiçōes, que poderiam ser realmente protagonistas na melhoria da qualidade da educação brasileira e mobilizadoras da escola em direção a novas práticas educacionais.

A existência de grande pressão por resultados nas avaliações externas é enfatizada entre os entrevistados das ETEs. Para alguns, essa pressão foi diminuindo à medida que a quantidade de escolas vinculadas ao PEI foi aumentando e atingindo as metas de governo, apesar de estar longe da universalização a que o entrevistado se refere: "Então, agora que essa modalidade de ensino se universalizou mais, então essa pressäo ficou mais leve, diminuiu mais. Mas a gente procura também ficar atento em relaçâo a isso, procurando fazer um trabalho da melhor maneira possivel" (Tony - ETE). Contudo, para a maioria, as pressōes por resultados vêm produzindo números que não condizem com o que acontece nas escolas em termos de aprendizagem:

Para o Estado, só interessa números, na realidade. Se a educação fosse levada a sério, obviamente não se teria preocupação daque- 
les que não têm um bom desempenho terem que ser aprovados de todo jeito, porque o Estado exige que tenha uma determinada porcentagem (Adailton — ETE).

A relação que os entrevistados das instituições federais e estaduais analisadas estabelecem entre as avaliaçóes externas e a organização do trabalho pedagógico no EMI tem aproximaçóes e distanciamentos. Os docentes e gestores do IFPE, a princípio, não percebem a existência dessa influência, ao náo identificarem um sistema de responsabilização baseado em metas, bonificaçóes e sançóes, como acontece com a rede estadual de Pernambuco, entretanto todos reconhecem que as avaliaçóes externas pressionam o currículo de maneira a gerar fragmentação entre a formação profissional e a formação propedêutica, por um lado, e, por outro, o estreitamento curricular caracterizado pela ênfase nas disciplinas propedêuticas, ou seja, aquelas que são necessárias para estabelecer posição no ranqueamento do IDEB, sobretudo no caso das ETEs, ou que são cobradas no ENEM, como no IFPE.

\section{Conclusões}

A concepção predominante de EMI dos docentes e gestores das ETEs e do IFPE é a de educação integrada como qualificação para o mercado de trabalho, sendo qualificação entendida como competências, saberes e conhecimentos requeridos pelo mercado. Entre os entrevistados das ETEs, essa concepçáo coexiste com a de educação integral que fundamenta o PEI, na visão de educação interdimensional.

Identificamos ainda uma disputa de concepçóes de educação integrada nos documentos das Diretrizes Curriculares (BRASIL, 2012a; 2012b) que também se manifesta entre os entrevistados, entre uma concepção que se restringe à mera formalidade da articulação entre a formação técnica profissional e a propedêutica em um mesmo currículo (BRASIL, 2012b); e uma que preconiza a integração entre trabalho, ciência, tecnologia e cultura (BRASIL, 2012a). Além disso, também apontamos, no texto das diretrizes, uma disputa entre a ótica da empregabilidade e da formação por competências, por um lado, e, por outro lado, a da formação integrada numa perspectiva de formação humana.

Nesse processo de disputa entre as concepçóes, as avaliaçóes externas são elementos fundamentais a serem levados em conta, pela própria importância e centralidade da avaliação nas definiçóes atuais das políticas educacionais brasileiras, sobretudo considerando a noção de qualidade da educação que vem sendo adotada para a gestão dessas políticas. Desde o lançamento do PDE (2007), que insere o IDEB como referência de qualidade da educação, até mesmo orientando o repasse do orçamento da educaçáo para as redes de ensino estaduais e 
municipais, os resultados dos alunos, das escolas e das redes de ensino em testes estandardizados e a perspectiva da responsabilização dos professores e das escolas por esses resultados constituem a espinha dorsal dessas políticas.

Tratando-se do ensino médio, o EMI também é pressionado pelo ENEM, tanto no que diz respeito ao atrelamento curricular às exigências que o exame começa a impor nos projetos federais ligados ao PDE, de indução de políticas estaduais e municipais, quanto no que concerne ao atrelamento dessa adesão ao Plano de Metas Compromisso Todos pela Educação, cuja lógica é a do empresariado.

As políticas educacionais baseadas na avaliação por resultados interferem na dinâmica escolar, mediante a reduçáo da autonomia da escola na formulação e no desenvolvimento do seu projeto político-pedagógico, até mesmo no sentido de identificar e enfrentar os limites impostos pelas condiçóes estruturais da própria escola e de seus sujeitos. Nesse sentido, manifestam-se diferenças entre as instituiçóes federais e estaduais, uma vez que o bom desempenho dos estudantes do IFPE se deve também ao bom desempenho inicial, no concorrido processo de seleção desses estudantes. Esse é o principal motivo para os entrevistados dessa instituição não terem valorizado em suas respostas possíveis dificuldades que pudessem ser geradas pelas avaliaçóes externas. Já entre os entrevistados das ETEs, essa preocupação foi recorrente, sobretudo porque existe ênfase da própria rede de ensino na busca por melhores colocações no ranking do IDEB.

Muitos estudos evidenciam a interferência das políticas de avaliação externa no trabalho escolar, como os de Freitas (2012; 2014). Não obstante, a contribuição da presente análise está em enfocar a interferência como um obstáculo à consecução do projeto de EMI em escolas de uma rede estadual e de um instituto federal, demonstrando que, mesmo sendo realidades específicas, tal obstáculo tende a se manifestar como contradiçóes de um mesmo fenômeno: a hegemonia do pensamento empresarial na educação brasileira.

No que se refere ao projeto de EMI, a pesquisa revela o quanto a concepçáo de formação integrada que o define está distante da realidade estudada. De um lado, mantém-se a dicotomia entre formaçáo para o mercado de trabalho e formaçáo para o prosseguimento de estudos, de modo que o bom desempenho dos estudantes nas avaliaçóes externas ora é valorizado pelo cumprimento da função propedêutica, ora é criticado por afastá-los da formação técnica. De outro lado, o comprometimento da autonomia escolar em nome do cumprimento das metas de avaliação redunda no estreitamento curricular e na intensificação do trabalho docente e discente, o que se torna obstáculo para a superação da mencionada dicotomia e para a construção de um projeto de formação integrada dos estudantes. 


\section{Notas}

1. Entre as 36 estratégias para a implementação da meta 7 do PNE, que versam sobre a melhoria da qualidade do ensino, 11 se referem às avaliaçóes, e não a aspectos nem a ações objetivas necessários à promoção da necessária melhoria.

2. Incluindo organismos multilaterais como a Organização para a Cooperação e Desenvolvimento Econômico (OCDE), o Banco Mundial, a Organizaçáo das Naçóes Unidas (ONU) e a Organização das Nações Unidas para a Educação, a Ciência e a Cultura (UNESCO).

3. Que revoga o Decreto no 2.208, de 17 de abril de 1997.

4. Disponível em: <http://basenacionalcomum.mec.gov.br/images/pdf/0_BNCC-Final_Apresentacao.pdf $>$. Acesso em: 5 out. 2017.

\section{Referências}

APPLE, M.W. Produzindo diferença: neoliberalismo, neoconservadorismo e a política de reforma educacional. Linhas Críticas, Brasília, v. 21, n. 46, p. 606-644, set./dez. 2015.

BOANAFINA, A.; BOANAFINA, L.; WERMELINGER, M. A educação profissional técnica de nível médio em saúde na Rede Federal de Educação. Trabalho, Educação e Saúde, Rio de Janeiro, v. 15, n. 1, p. 73-93, jan./abr. 2017. http://dx.doi.org/10.1590/19817746-sol00034

BORMANN, A.C. O Programa Ensino Médio Inovador e a Proposta de Integração Curricular para o Ensino Médio. Revista Ensino Interdisciplinar, Mossoró, v. 3, n. 7, jan. 2017.

BRASIL. Decreto no 5.154, de 23 de julho de 2004. Brasília: Presidência da República, 2004. . Decreto $n^{\circ}$ 6.094, de 24 de abril de 2007: Plano de Metas Compromisso Todos pela Educação. Brasília: Presidência da República, 2007a.

- Decreto $n^{\circ}$ 6.302, de 12 de dezembro de 2007: institui o Programa Brasil Profissionalizado. Brasília: Presidência da República, 2007b.

Lei no 11.741, de 16 de julho de 2008: altera dispositivos da Lei no 9.394/96. Brasília: Presidência da República, 2008a.

Lei no 11.892, de 29 de dezembro de 2008: institui a Rede Federal de Educação Profissional, Científica e Tecnologia e cria os Institutos Federais de Educação, Ciência e Tecnologia. Brasília: Presidência da República, 2008b.

- Lei no 12.005, de 25 de junho de 2014: aprova o Plano Nacional de Educação PNE. Brasília: Presidência da República, 2014a.

BRASIL. Decreto no 8.268, de 18 de junho de 2014- altera o Decreto no 5.154, de 23 de julho de 2004. Presidência da República, 2014b. 
Lei no 12.513 de 26 de outubro de 2011: institui o Programa Nacional de Acesso ao Ensino Técnico e Emprego (Pronatec). Brasília: Presidência da República, 2011.

. Leino 13.415, de 16 de fevereiro de 2017: institui a Política de Fomento à Implementaçáo de Escolas de Ensino Médio Integral. Brasília: Presidência da República, 2017.

Portaria $n^{\circ}$ 971, de 9 de outubro de 2009: institui o Programa Ensino Médio Inovador. Brasília: Ministério da Educação, 2009.

Resolução no 2, de 30 de janeiro de 2012: define Diretrizes Curriculares Nacionais para o Ensino Médio. Brasília: Conselho Nacional de Educação/Câmara de Educação Básica, 2012a.

. Resolução no 6, de 20 de setembro de 2012: define Diretrizes Curriculares Nacionais para a Educação Profissional Técnica de Nível Médio. Brasília: Conselho Nacional de Educação/Câmara de Educação Básica, 2012b.

CAÚ, J.N.A. A juventude do curso técnico integrado em agropecuária do IFPE: desejos, expectativas e experiências vivenciadas para a construção dos seus projetos de vida. Tese (Doutorado) - Programa de Pós-Graduação em Educação, Universidade Federal de Pernambuco, 2017.

CURY, C.R.J. Educação e contradição: elementos metodológicos para uma teoria crítica do fenômeno educativo. 6. ed. São Paulo: Cortez, 1995.

FERREIRA, E.B. A contrarreforma do Ensino Médio no contexto da nova ordem e progresso. Educação e Sociedade, Campinas, v. 38, n. 139, p. 293-308, abr.-jun. 2017. DOI: 10.1590/ES0101-73302017176594

FERRETTI, C.J.; SILVA, M.R. da. Reforma do Ensino Médio no contexto da Medida Provisória no 746/2016: Estado, Currículo e Disputas por Hegemonia. Educaçáo e Sociedade, Campinas, v. 38, n. 139, p. 385-404, abr.-jun. 2017. http://dx.doi.org/10.1590/ es0101-73302017176607

FREITAS, L.C. de. A importância da avaliação: em defesa de uma responsabilização participativa. Em Aberto, Brasília, v. 29, n. 96, p. 127-139, maio/ago. 2016. http://dx.doi. org/10.24109/2176-6673.emaberto.29i96.\%25p

. Os reformadores empresariais da educação: da desmoralização do magistério à destruição do sistema público de educação. Educação e Sociedade, Campinas, v. 33, n. 119 , p. 379-404, abr.-jun. 2012. http://dx.doi.org/10.1590/S0101-73302012000200004

. Os reformadores empresariais da educação e a disputa pelo controle do processo pedagógico na escola. Educação e Sociedade, Campinas, v. 35, n. 129, p. 1085-1114, out.dez. 2014. http://dx.doi.org/10.1590/ES0101-73302014143817

FRIGOTTO, G.; CIAVATTA, M.; RAMOS, M. Ensino médio integrado: concepção e contradiçôes. São Paulo: Cortez, 2005.

GESQUI, L.C. O IDEB como parâmetro de qualidade da Educação Básica no Brasil: algumas preocupaçôes. Cadernos de Pesquisa, São Luís, v. 23, n. 3, set./dez. 2016. http:// dx.doi.org/10.18764/2178-2229.v23n3p88-99 
GRAMSCI, A. Cadernos do Cárcere: Maquiavel - notas sobre o Estado e a Política. Rio de Janeiro. Civilização Brasileira, 2000. v. 3.

MORAES, C.S.V. O ensino médio e as comparações internacionais: Brasil, Inglaterra e Finlândia. Educação e Sociedade, Campinas, v. 38, n. 139, p. 405-429, abr.-jun. 2017. DOI: $10.1590 / \mathrm{ES} 0101-73302017177657$

ORGANIZAÇÃO DAS NAÇÓES UNIDAS PARA A EDUCAÇÃO, A CIÊNCIA E A CULTURA (UNESCO). Educação: um tesouro a descobrir. Relatório para a UNESCO da Comissão Internacional sobre Educação para o Século XXI. Paris: Cortez/UNESCO/ MEC, 1997.

RAMOS, M.N. Da qualificação à competência: deslocamento conceitual na relação trabalhoeducação. Tese (Doutorado) - Faculdade de Educação, Universidade Federal Fluminense, 2001.

. Ensino Médio Integrado: lutas históricas e resistências em tempos de regressão. In: ARAÚJO, A.C.; SILVA, C.N. (Orgs.). Ensino Médio Integrado no Brasil: fundamentos, práticas e desafios. Brasília: Ed. IFB, 2017. p. 20-43.

. Políticas educacionais: da pedagogia das competências à pedagogia históricocrítica. In: BARBOSA, M.V.; MILLER, S.; MELLO, S.A. (Orgs.). Teoria históricocultural: questóes fundamentais para a educação escolar. São Paulo: Cultura Acadêmica, 2016. v. 1. p. 59-76.

ROSA, A.V. do N.; MARCONDES, M.I.; COELHO, L.M.C.C. Educação Integral e(m) Tempo Integral: analisando as Organizaçóes Curriculares apresentadas nas pesquisas publicadas entre os anos 2000 e 2012. Revista COCAR, Belém, v. 10, n. 20, p. 27-51, ago./ dez. 2016.

SILVA, K.N.P.; SILVA, J.A. de A. da. Política de Avaliação e Programa de Educação Integral no Ensino Médio da Rede Estadual de Pernambuco: os limites da centralidade da avaliação nas políticas educacionais. Práxis Educativa, Ponta Grossa, p. 736-756, v. 11, n. 3, set./dez. 2016. http://dx.doi.org/10.5212/PraxEduc.v.11i3.0012

Trabalho docente e educação integrada nas escolas técnicas estaduais de Pernambuco. Educar em Revista, Curitiba, v. 33, n. 65, p. 237-247, jul./set. 2017. DOI: $10.1590 / 0104-4060.49328$

Recebido em 19 de outubro de 2017.

Aceito em 16 de fevereiro de 2018.

(C) 2018 Centro de Estudos Educação e Sociedade - CEDES Este é um artigo de acesso aberto distribuído nos termos de licença Creative Commons. 